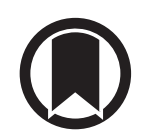

CrossMark

\title{
Disease severity and clinical outcomes of community-acquired pneumonia caused by non-influenza respiratory viruses in adults: a multicentre prospective registry study from the CAP-China Network
}

\author{
Fei Zhou 1,2,3,37, Yimin Wang 1,2,3,37, Yingmei Liü,2,3,37, Xuedong Liü,37, Li Gu 5,37, \\ Xiaoju Zhang ${ }^{6,37}$, Zenghui Pu ${ }^{7,37}$, Guoru Yang ${ }^{8,37}$, Bo Liu ${ }^{9,37}$, Qingrong Nie ${ }^{10}$, \\ Bing Xue ${ }^{11}$, Jing Feng ${ }^{12}$, Qiang Guo ${ }^{13}$, Jianhua Liu ${ }^{14}$, Hong Fan ${ }^{15}$, Jin Chen ${ }^{16}$, \\ Yongxiang Zhang ${ }^{17}$, Zhenyang $\mathrm{Xu}^{18}$, Min Pang ${ }^{19}$, Yu Chen ${ }^{20}$, Xiuhong $\mathrm{Ni}^{21}$, \\ Zhigang $\mathrm{Cai}^{22}$, Jinfu $\mathrm{Xu}^{23}$, Kun Peng ${ }^{24}$, Xiangxin Li ${ }^{25}$, Pingchao Xiang ${ }^{26}$, \\ Zuoqing Zhang ${ }^{27}$, Shujuan Jiang ${ }^{28}$, Xin Su ${ }^{29}$, Jie Zhang ${ }^{30}$, Yanming Li ${ }^{31}$, \\ Xiuhong $\mathrm{Jin}^{32}$, Rongmeng Jiang ${ }^{33}$, Jianping Dong ${ }^{34}$, Yuanlin Song ${ }^{35}$, \\ Hong Zhou ${ }^{36}$, Chen Wang ${ }^{1,2,3,38}$ and Bin Cao ${ }^{1,2,3,38}$ and the CAP-China Network
}

@ERSpublications

The high incidence of complications in non-influenza viral pneumonia and similar impact of noninfluenza viruses relative to influenza virus on disease severity and outcomes suggest more attention should be given to CAP caused by non-influenza viruses http://bit.ly/2vRTvFK

Cite this article as: Zhou F, Wang Y, Liu Y, et al. Disease severity and clinical outcomes of communityacquired pneumonia caused by non-influenza respiratory viruses in adults: a multicentre prospective registry study from the CAP-China Network. Eur Respir J 2019; 54: 1802406 [https://doi.org/10.1183/ 13993003.02406-2018].

ABSTRACT Although broad knowledge of influenza viral pneumonia has been established, the significance of non-influenza respiratory viruses in community-acquired pneumonia (CAP) and their impact on clinical outcomes remains unclear, especially in the non-immunocompromised adult population.

Hospitalised immunocompetent patients with CAP were prospectively recruited from 34 hospitals in mainland China. Respiratory viruses were detected by molecular methods. Comparisons were conducted between influenza and non-influenza viral infection groups.

In total, 915 out of 2336 adult patients with viral infection were enrolled in the analysis, with influenza virus $(28.4 \%)$ the most frequently detected virus, followed by respiratory syncytial virus (3.6\%), adenovirus (3.3\%), human coronavirus (3.0\%), parainfluenza virus (2.2\%), human rhinovirus (1.8\%) and human metapneumovirus (1.5\%). Non-influenza viral infections accounted for $27.4 \%$ of viral pneumonia. Consolidation was more frequently observed in patients with adenovirus infection. The occurrence of complications such as sepsis $(40.1 \%$ versus $39.6 \% ; \mathrm{p}=0.890)$ and hypoxaemia $(40.1 \%$ versus $37.2 \%$; $\mathrm{p}=0.449$ ) during hospitalisation in the influenza viral infection group did not differ from that of the noninfluenza viral infection group. Compared with influenza virus infection, the multivariable adjusted odds ratios of CURB-65 (confusion, urea $>7 \mathrm{mmol} \cdot \mathrm{L}^{-1}$, respiratory rate $\geqslant 30$ breaths $\cdot \mathrm{min}^{-1}$, blood pressure $<90 \mathrm{mmHg}$ (systolic) or $\leqslant 60 \mathrm{mmHg}$ (diastolic), age $\geqslant 65$ years) $\geqslant 3$, arterial oxygen tension/inspiratory oxygen fraction $<200 \mathrm{mmHg}$, and occurrence of sepsis and hypoxaemia for non-influenza respiratory virus infection were 0.87 (95\% CI 0.26-2.84), 0.72 (95\% CI 0.26-1.98), 1.00 (95\% CI 0.63-1.58) and 1.05 (95\% CI $0.66-1.65$ ), respectively. The hazard ratio of 90 -day mortality was 0.51 (95\% CI $0.13-1.91$ ).

The high incidence of complications in non-influenza viral pneumonia and similar impact of noninfluenza respiratory viruses relative to influenza virus on disease severity and outcomes suggest more attention should be given to CAP caused by non-influenza respiratory viruses. 


\section{Introduction}

Community-acquired pneumonia (CAP) is the leading cause of death worldwide among communicable diseases [1]. The development of molecular diagnostic techniques has markedly improved our ability to identify viruses, with numerous studies having reported a high prevalence of viral infections in patients with CAP [2]. A recent meta-analysis incorporating 31 observational studies showed that the proportion of viral infection was $24.5 \%$ in hospitalised patients with CAP, with influenza virus types A and B (IFV) most frequently identified, followed by human rhinovirus (HRV), respiratory syncytial virus (RSV) and human coronavirus $(\mathrm{CoV})[2]$.

Previous studies have established the clinical features, complications and outcomes associated with influenza viral pneumonia $[3,4]$. However, most data concerning non-influenza viral pneumonia were derived from case reports and case series, since non-influenza respiratory viruses were most frequently known as the cause of upper respiratory tract infections [3]. Additionally, the majority of studies focusing on non-influenza respiratory viruses in adults with pneumonia were conducted in populations with limited generalisability to CAP patients, such as immunocompromised or frail elderly patients, residents of long-term facilities, cases with underlying lung diseases, or critically ill people [5-11]. Therefore, the significance of non-influenza respiratory viruses in pneumonia and their specific impact on clinical outcomes has not been established in immunocompetent adult patients with CAP.

Here, we performed a national, prospective, multicentre study in order to evaluate the impact of non-influenza respiratory viruses compared with IFV on disease severity, proportion of patients achieving clinical stability within the first 3 days at the hospital, complications, intensive care unit (ICU) admission, length of hospital stay and 90-day mortality in immunocompetent adult patients with CAP.

Affiliations: ${ }^{1}$ Dept of Pulmonary and Critical Care Medicine, Center for Respiratory Diseases, China-Japan Friendship Hospital, Institute of Respiratory Medicine Chinese Academy of Medical Science, National Clinical Research Center of Respiratory Diseases, Beijing, China. ${ }^{2}$ Clinical Center for Pulmonary Infections, Capital Medical University, Beijing, China. ${ }^{3}$ Tsinghua University-Peking University Joint Center for Life Sciences, Beijing, China. ${ }^{4}$ Dept of Respiratory Medicine, Qingdao Municipal Hospital, Qingdao, China. ${ }^{5}$ Dept of Infectious Diseases, Beijing Chao-Yang Hospital, Capital Medical University, Beijing, China. ${ }^{6}$ Dept of Respiratory Medicine, Henan Provincial People's Hospital, Zhengzhou, China. ${ }^{7}$ Dept of Infectious Diseases, Yantai Yu Huang-Ding Hospital, Yantai, China. ${ }^{8}$ Dept of Pulmonary and Critical Care Medicine, Weifang No. 2 People's Hospital, Weifang, China. ${ }^{9}$ Dept of Respiratory and Critical Care Medicine, Linzi District People's Hospital, Zibo, China. ${ }^{10}$ Dept of Respiratory and Critical Care Medicine, Liangxiang Hospital, Beijing, China. ${ }^{11}$ Dept of Respiratory Medicine, Chuiyangliu Hospital Affiliated to Tshinghua University, Beijing, China. ${ }^{12}$ Dept of Respiratory Medicine, General Hospital of Tianjin Medical University, Tianjin, China. ${ }^{13}$ Dept of Respiratory, Emergency and Critical Care Medicine, First Affiliated Hospital of Soochow University, Jiangsu, China. ${ }^{14}$ Dept of Respiratory Medicine, Beijing Huairou Hospital of University of Chinese Academy of Science, Beijing, China. ${ }^{15}$ Dept of Pulmonary and Critical Care Medicine, West China Hospital, Sichuan University, Chengdu, China.

${ }^{16}$ Dept of Respiratory Medicine, Fuxing Hospital, Capital Medical University, Beijing, China. ${ }^{17}$ Dept of Respiratory Medicine, Daxing Teaching Hospital, Capital Medical University, Beijing, China. ${ }^{18}$ Dept of Pulmonary and Critical Care Medicine, Beijing Luhe Hospital, Capital Medical University, Beijing, China. ${ }^{19}$ Dept of Respiratory Medicine, First Hospital of Shanxi Medical University, Taiyuan, China. ${ }^{20}$ Dept of Pulmonary and Critical Care Medicine, Shengjing Hospital of China Medical University, Beijing China. ${ }^{21}$ Dept of Respiratory Medicine, Xuanwu Hospital, Capital Medical University, Beijing, China. ${ }^{22}$ Dept of Pulmonary and Critical Care Medicine, Second Hospital of Hebei Medical University, Shijiazhuang, China. ${ }^{23}$ Dept of Pulmonary and Critical Care Medicine. Shanghai Pulmonary Hospital, Shanghai, China. ${ }^{24}$ Dept of Respiratory Medicine, Beijing No. 6 Hospital, Beijing, China. ${ }^{25}$ Dept of Pulmonary and Critical Care Medicine, Beijing Changping Hospital, Beijing, China. ${ }^{26}$ Dept of Pulmonary and Critical Care Medicine, Peking University Shougang Hospital, Beijing, China. ${ }^{27}$ Dept of Respiratory Medicine, Beijing Shijingshan Hospital, Beijing, China. ${ }^{28}$ Dept of Pulmonary and Critical Care Medicine, Shandong Province Hospital, Jinan, China. ${ }^{29}$ Dept of Respiratory Medicine, Nanjing General Hospital of Nanjing Military Command, PLA, Nanjing, China. ${ }^{30}$ Dept of Respiratory Medicine, Beijing Tiantan Hospital, Capital Medical University, Beijing, China. ${ }^{31}$ Dept of Pulmonary and Critical Care Medicine, Beijing Hospital, Beijing, China. ${ }^{32}$ Dept of Respiratory Medicine, Beijing Pinggu Hospital, Beijing, China. ${ }^{33}$ Infectious Disease Diagnosis and Treatment Center, Beijing Ditan Hospital, Capital Medical University, Beijing, China. ${ }^{34}$ Dept of Infectious Diseases, Beijing Haidian Hospital, Haidian Section of Peking University Third Hospital, Beijing, China. ${ }^{35}$ Dept of Pulmonary and Critical Care Medicine, Zhongshan Hospital, Fudan University, Shanghai, China. ${ }^{36}$ Dept of Respiratory Medicine, Beijing Electric Power Hospital, Beijing, China. ${ }^{37}$ These authors contributed equally to this work. ${ }^{38}$ These authors contributed equally to this work.

Correspondence: Bin Cao, Dept of Pulmonary and Critical Care Medicine, National Clinical Research Center of Respiratory Diseases, 2 Yinghua Dongjie, Chao-Yang District, Beijing, 100029, China.

E-mail: caobin_bena163.com

This article has supplementary material available from erj.ersjournals.com

Received: Dec 192018 | Accepted after revision: May 022019 


\section{Methods}

\section{Study setting and design}

The CAP-China study, a prospective multicentre observational study, was conducted in 34 hospitals from 10 provinces of mainland China (figure 1), with all of the hospitals located in urban areas (supplementary table S1). From October 1, 2015 to June 30, 2017, patients with CAP admitted to the emergency department, general wards or ICU were screened for enrolment (supplementary figure S1). Written informed consent was obtained from all patients or their caregivers before enrolment. The CAP-China study was approved by the institutional review board of the China-Japan Friendship Hospital and was registered at ClinicalTrials.gov with identifier NCT02492425.

\section{Study population}

Patients aged $\geqslant 14$ years and hospitalised for CAP were enrolled on admission. CAP was diagnosed according to the 2007 Infectious Diseases Society of America (IDSA)/American Thoracic Society (ATS) guidelines [12].

Patients were excluded if one of the following criteria was met: 1) hospitalisation within the previous 90 days or enrolled in this study within the previous 30 days; 2) being immunocompromised: cancer with neutropenia (absolute neutrophil count $<500 \mathrm{~mm}^{-3}$ ), haematological malignancies, solid malignancies receiving chemotherapy during the previous 3 months, solid organ or bone marrow transplant, active graft versus host disease, bronchiolitis obliterans, HIV infection, immunoglobulin deficiency, using immunosuppressive agents, or current treatment with systemic corticosteroids $(\geqslant 20 \mathrm{mg}$ prednisone per day or equivalent) for $>30$ continuous days before illness onset; 3) receipt of a tracheotomy, insertion of a percutaneous endoscopic gastrostomy tube or presentation of cystic fibrosis; or 4) had a clear alternative diagnosis at the end of follow-up that included lung cancer, pulmonary tuberculosis, interstitial lung disease, pulmonary embolism, pulmonary oedema or allergic bronchopulmonary aspergillosis.

2718 hospitalised CAP patients were eligible for enrolment during the study period. A total of 382 cases were excluded: refusal to consent $(n=69)$, failure in sampling $(n=158)$, being immunocompromised $(n=37)$, final diagnosis of tuberculosis or non-pneumonia illness $(n=58)$, or being lost to follow-up $(n=60)$. Of the 2336 participants enrolled in the CAP-China study, 1421 were negative for viral detection. Finally, a total of 915 patients with positive viral detection were included in this analysis (figure 2).

\section{Data collection and quality control}

Before study initiation, all local principal investigators and study staff received extensive training on the protocol. Trained staff interviewed patients (or their caregivers) within $24 \mathrm{~h}$ after enrolment, with

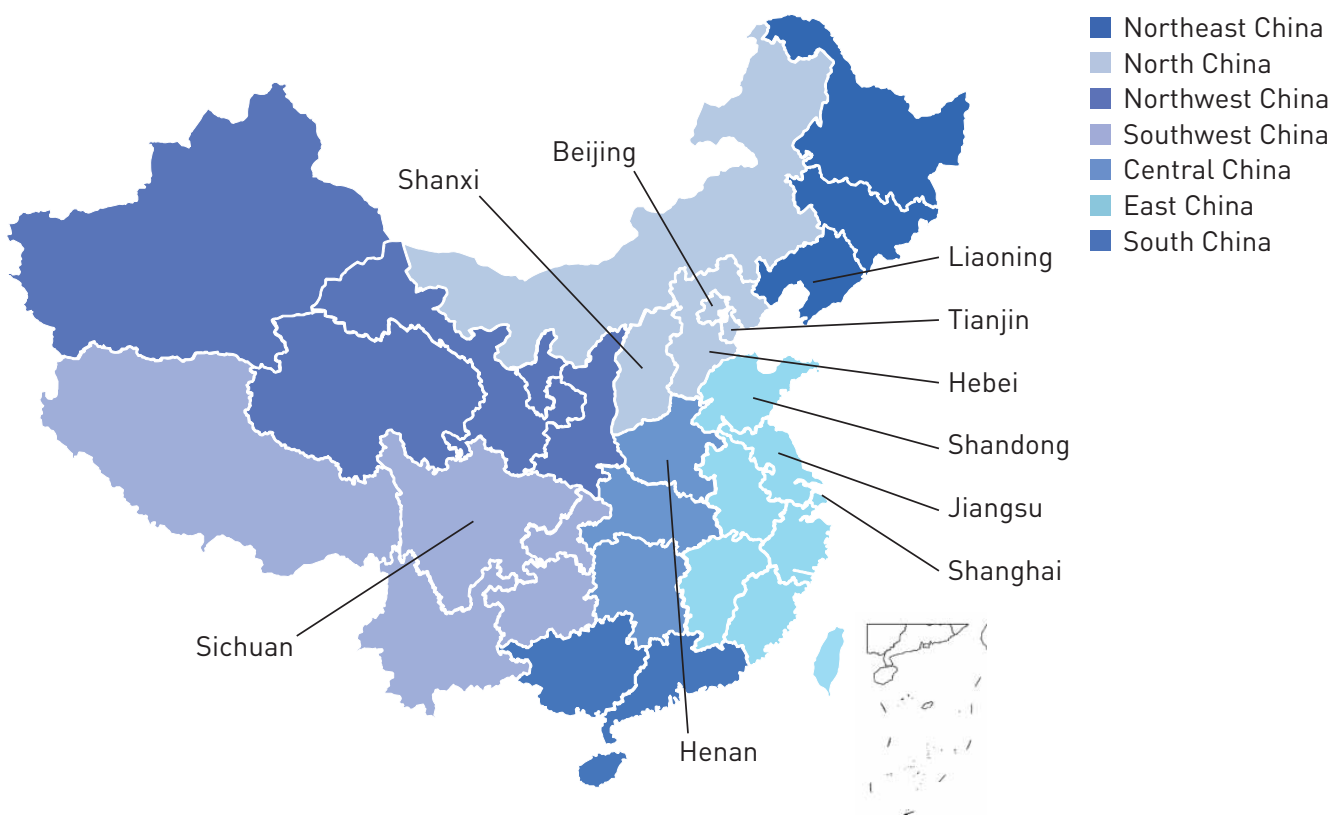

FIGURE 1 Patients were enrolled from five of the seven geographical locations in mainland China, including Beijing, Tianjin, Hebei and Shanxi provinces in North China; Shanghai, Shandong and Jiangsu provinces in East China; Henan province in Central China; Sichuan province in Southwest China; and Liaoning province in Northeast China. 


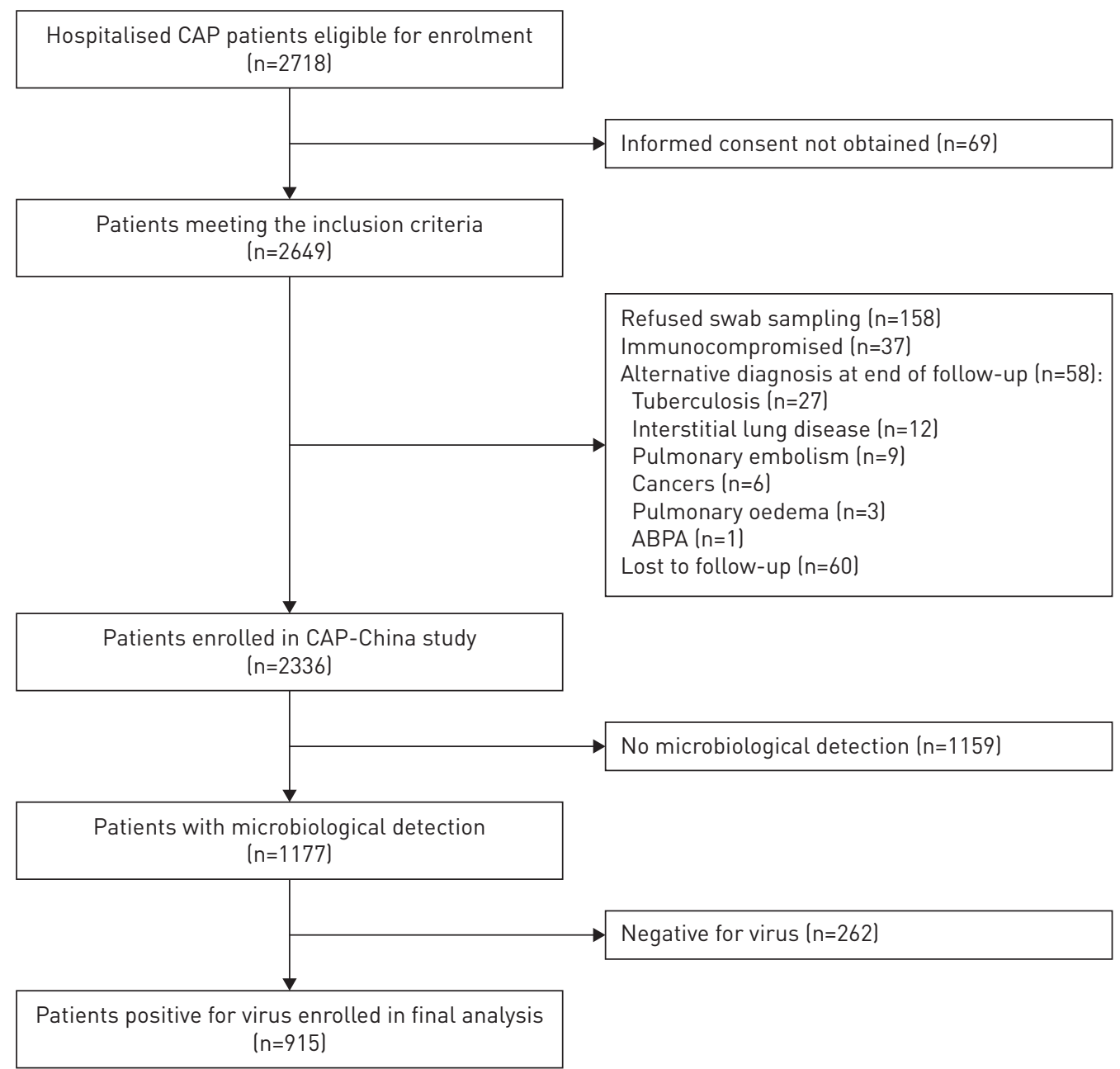

FIGURE 2 Study flowchart. CAP: community-acquired pneumonia; ABPA: allergic bronchopulmonary aspergillosis.

demographic information, comorbidities, clinical manifestations, vital signs, laboratory results and microbiology data, antimicrobial use, complications, and outcomes collected using a standardised case report form. During a 90-day follow-up period, all-cause death was recorded by telephone interview. All information was uploaded into an electronic database (www.chinapneumonia.cn) by trained clinical research coordinators and systematic data checks were performed automatically online in order to detect logical errors or extremes. For each case, $10 \%$ of the data were selected at random and checked against the original medical records by clinical research associates in order to confirm accuracy and completeness.

\section{Specimen collection and testing}

Two nasopharyngeal swabs were obtained from all patients $(n=2332)$ immediately upon entry to the emergency department, general wards or ICU. One swab was collected for rapid influenza antigen testing on site; the other swab was placed in universal transport medium and stored at $-80^{\circ} \mathrm{C}$ for PCR analysis in the central laboratory (National Clinical Research Center of Respiratory Diseases, China-Japan Friendship Hospital, Beijing, China). On-site urine antigen tests for Streptococcus pneumoniae and Legionella pneumophila were performed in all patients within $24 \mathrm{~h}$ after admission. Blood for cultures was obtained from 610 patients with a temperature $\geqslant 38.5^{\circ} \mathrm{C}$ within $48 \mathrm{~h}$ of admission, with $73.4 \%$ of them having received empirical antibiotics treatment. A total of 1229 patients had qualified sputum or endotracheal aspirate collected within $48 \mathrm{~h}$ after admission, with 868 of these patients having already received empirical CAP antibiotics. On-site Gram staining and bacterial cultures were performed according to routine microbiological guidance. Sputum, endotracheal aspirate and bronchoalveolar lavage fluid (BALF) samples were stored at $-80^{\circ} \mathrm{C}$ until PCR testing in the central laboratory. 


\section{Pathogen detection}

Viral aetiology was considered positive if one of the following criteria was met: 1) detection of respiratory virus in sputum, endotracheal aspirate, BALF or nasopharyngeal swabs by real-time PCR (TaqMan Array Microfluidic Cards; Applied Biosystems, Foster City, CA, USA) [13], including RSV, IFV, parainfluenza virus (PIV), HRV, CoV, human metapneumovirus (HMPV) and adenovirus (AdV); or 2) positive antigen for IFV (Clearview Exact Influenza A\&B; Alere, Waltham, MA, USA).

Bacterial or atypical pathogens were considered positive if one of the following criteria was met: 1) positive bacterial culture from blood or pleural fluid; 2) positive urinary antigen for L. pneumophila (Binax Now; Trinity Biotech, Bray, Ireland) or S. pneumoniae (Binax Now; Emergo Europe, Amsterdam, The Netherlands); 3) detection of Mycoplasma pneumoniae or Chlamydia pneumoniae in sputum, BALF, endotracheal aspirate or nasopharyngeal swabs by real-time PCR (Shanghai Zhijiang Bio-Tec, Shanghai, China) [14]; 4) detection of L. pneumophila in sputum, BALF or endotracheal aspirate by real-time PCR (Shanghai Zhijiang Bio-Tec) [14]; or 5) bacteria with moderate to heavy growth (graded as $>3+$ growth) in qualified sputum or endotracheal aspirate, or quantified culture in BALF of $\geqslant 10^{4} \mathrm{CFU} \cdot \mathrm{mL}^{-1}$. In this study, qualified samples were defined as more than 25 leukocytes and less than 10 epithelial cells per magnified field (at $\times 100$ magnification).

\section{Definitions}

Hypoxaemia was defined as arterial oxygen tension $\left(\mathrm{PaO}_{2}\right)$ /inspiratory oxygen fraction $\left(\mathrm{FIO}_{2}\right)<300 \mathrm{mmHg}$ [15]. Sepsis was diagnosed based on the revised criteria defined by Singer et al. [16], i.e. Sequential Organ Failure Assessment score $\geqslant 2$. Pneumonia severity was assessed by CURB-65 (confusion, urea $>7 \mathrm{mmol} \cdot \mathrm{L}^{-1}$, respiratory rate $\geqslant 30$ breaths $\cdot \mathrm{min}^{-1}$, blood pressure $<90 \mathrm{mmHg}$ (systolic) or $\leqslant 60 \mathrm{mmHg}$ (diastolic), age $\geqslant 65$ years) [17] and $\mathrm{PaO}_{2} / \mathrm{FIO}_{2}$. Clinical stability was defined according to the $2007 \mathrm{IDSA} /$ ATS guidelines [12]. Viral and bacterial co-infection was defined as detection of both viruses and bacteria [18]. Viral and M. pneumoniae/C. pneumoniae co-infection was defined as detection of both viruses and atypical pathogens. Mixed viral infection was defined as detection of two or more viruses.

\section{Statistical analysis}

Viral CAP patients were classified into three groups: influenza viral infection group, non-influenza viral infection group and mixed viral infection group. For the influenza or non-influenza viral infection group, only one virus was detected. Clinical features, CURB-65 $\geqslant 3$ and $\mathrm{PaO}_{2} / \mathrm{FIO}_{2}<200 \mathrm{mmHg}$ on admission, 24 and $72 \mathrm{~h}$ clinical stability, hypoxaemia and sepsis during hospitalisation, ICU admission, invasive ventilation, and 90-day mortality were compared between the influenza and non-influenza viral infection groups. Further comparisons were performed in different viral infection groups (IFV, CoV, HMPV, HRV, $\mathrm{AdV}, \mathrm{PIV}, \mathrm{RSV}$ and mixed viral infection). Continuous variables are presented as median (interquartile range (IQR)) and categorical variables are presented as number (percentage). The normality of data distribution was assessed and a Mann-Whitney U-test was used for non-normally distributed variables. A Chi-squared test was used to compare categorical variables. Univariate logistic regression analysis was used to estimate the odds ratios and 95\% confidence intervals of underlying diseases, clinical features, laboratory findings, severe disease, complications and mortality for the non-influenza viral infection group compared with the influenza viral infection group. A multivariable adjusted logistic regression model was used to estimate the effect of different viruses on disease severity (CURB-65 $\geqslant 3$ and $\mathrm{PaO}_{2} / \mathrm{FIO}_{2}<200 \mathrm{mmHg}$ on admission) and complications (sepsis and hypoxaemia during hospitalisation). Multivariable adjusted Cox regression was conducted to estimate the association between viral aetiology and 90-day mortality. All data were analysed with SPSS version 19.0 (SPSS, Chicago, IL, USA). A two-sided $\mathrm{p}<0.05$ was considered statistically significant. Bonferroni correction was used for multiple comparisons.

\section{Results}

\section{Patient characteristics}

The median (IQR) age of the 915 patients with viral infection was 59.0 (36.0-72.0) years and 55.2\% were male (table 1). A total of $426(46.6 \%)$ patients had comorbidities, with cardiovascular disease the most commonly observed $(31.3 \%)$, followed by diabetes (14.6\%) and chronic obstructive pulmonary disease (COPD) (4.5\%). The most common symptoms of patients with viral infection were cough (93.0\%), fever $(81.3 \%)$ and sputum $(81.3 \%)$, and $\sim 33 \%$ of patients had dyspnoea. 151 patients had received antiviral therapy in the emergency department or on admission, among which $98.7 \%$ represented empirical treatment. Neuraminidase inhibitors were the most commonly used antivirals (86\%), followed by ganciclovir (9\%), acyclovir (7\%) and ribavirin (2\%). The median (IQR) length of hospital stay in patients with viral infection was 10 (8-14) days and the 90-day mortality was $3.1 \%$.

Among the 915 patients, influenza viral infection, non-influenza viral infection and mixed viral infection was found in 581, 240 and 94 cases, respectively. The baseline characteristics of age, symptoms, underlying 
TABLE 1 Demographic characteristics, underlying diseases, clinical features and laboratory findings of hospitalised community-acquired pneumonia patients with viral infections

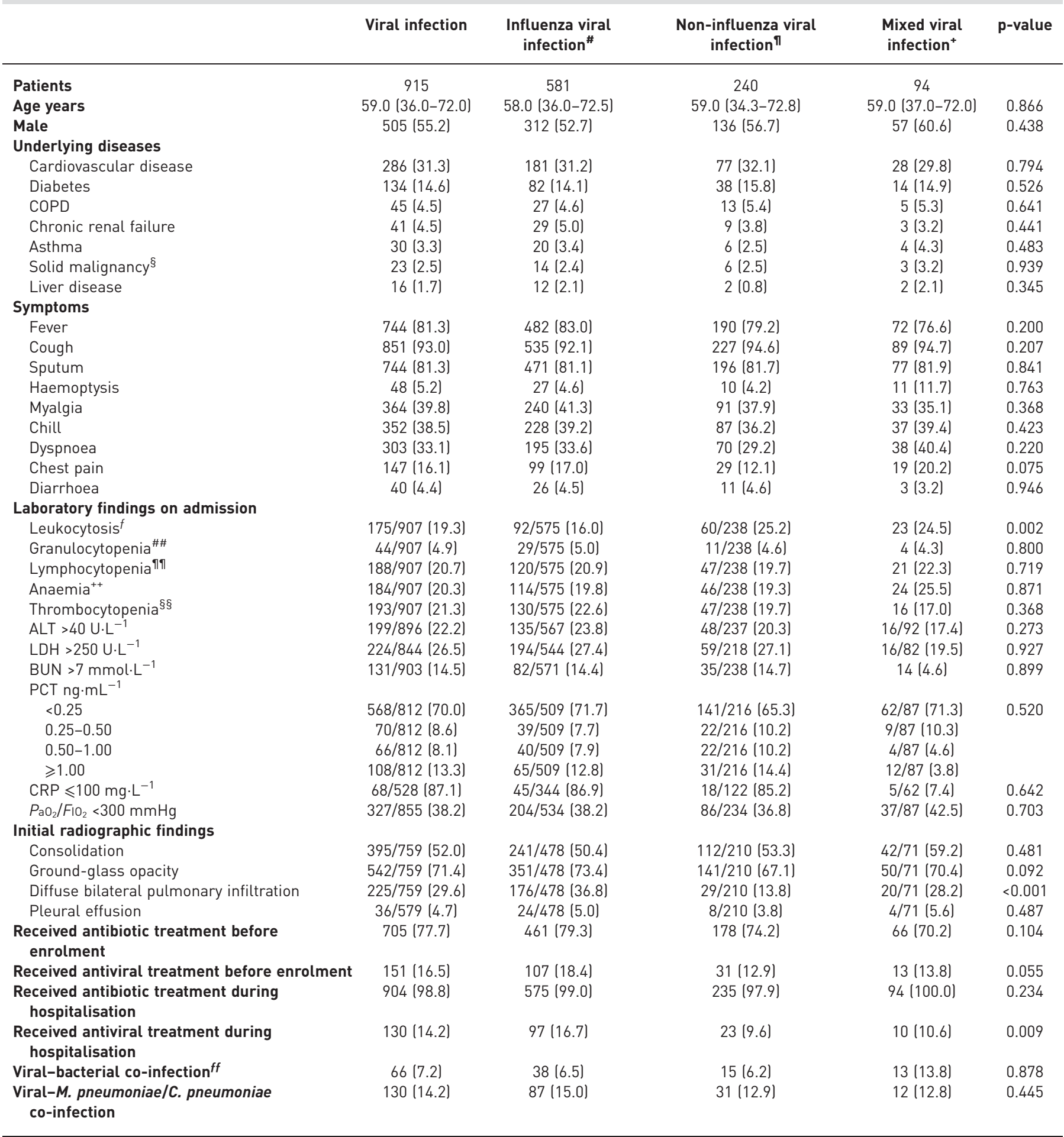

Data are presented as $n$, median (interquartile range) or $n / N(\%)$, unless otherwise stated. COPD: chronic obstructive pulmonary disease; ALT: alanine aminotransferase; LDH: lactate dehydrogenase; BUN: blood urea nitrogen; PCT: procalcitonin; CRP: C-reactive protein; $P$ a0 ${ }_{2}$ : arterial oxygen tension; $\mathrm{FlO}_{2}$ : inspiratory oxygen fraction; M. pneumoniae: Mycoplasma pneumoniae; C. pneumoniae: Chlamydia pneumoniae. ${ }^{\#}$ : only influenza virus with or without co-infection; ${ }^{9}$ : any non-influenza virus with or without co-infection; ${ }^{+}$: any two or more viruses; ${ }^{\S}$ : including $n=6$ lung cancer, $n=5$ colon cancer, $n=4$ stomach cancer, $n=4$ liver cancer, $n=2$ thyroid cancer, $n=1$ breast cancer and $n=1$ cervical cancer;

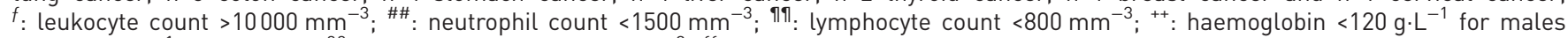
and $<110 \mathrm{~g} \cdot \mathrm{L}^{-1}$ for females; ${ }^{\S}$ : platelet count $<150000 \mathrm{~mm}^{-3}$; ff: includes typical bacteria and viruses co-infection ( $\mathrm{n}=57$ ) and $\mathrm{L}$. pneumophila and viruses co-infection (n=9). $p$-values are for the influenza viral infection group versus the non-influenza viral infection group. 
TABLE 2 Patients with positive virus detection

$\begin{array}{lc}\text { Viral detection only } & 645 \\ \text { One viral infection } & 452 \\ \text { Influenza A/B } & 45 \\ \text { Adenovirus } & 45 \\ \text { Respiratory syncytial virus } & 29 \\ \text { Human coronavirus } & 28 \\ \text { Parainfluenza virus 1-4 } & 24 \\ \text { Human rhinovirus } & 22 \\ \text { Human metapneumovirus } & 68 \\ \text { Mixed viral infection } & 66 \\ \text { Viral-bacterial co-infection" } & 130 \\ \text { Viral-M. pneumoniae/C. pneumoniae co-infection } & 6 \\ \text { Viral-bacterial-M. pneumoniae/C. pneumoniae co-infection" } & 6\end{array}$

Data are presented as n. M. pneumoniae: Mycoplasma pneumoniae; C. pneumoniae: Chlamydia pneumoniae. $\#$ : includes typical bacteria and viruses co-infection $(n=57)$ and $L$. pneumophila and viruses co-infection $(n=9) ; ~ ๆ$ : includes viruses, typical bacteria and M. pneumoniae/C. pneumoniae co-infection.

diseases and laboratory findings were similar between the influenza and non-influenza viral infection groups, except that leukocytosis was more common in the non-influenza viral infection group (25.2\% versus $16.0 \%$; OR 1.77, 95\% CI 1.23-2.56; $\mathrm{p}=0.002$ ) and diffuse bilateral pulmonary infiltration was more common in the influenza viral infection group ( $36.8 \%$ versus $13.8 \%$; OR $0.28,95 \%$ CI $0.18-0.42$; $\mathrm{p}<0.001$ ) (table 1 and supplementary table S2).

\section{Pathogen detection}

Among 2336 hospitalised patients with CAP, IFV (28.4\%) was the most frequently detected virus, followed by RSV (3.6\%), $\mathrm{AdV}$ (3.3\%) and $\mathrm{CoV}$ (3.0\%); mixed viral infection was observed in 68 patients (table 2). AdV infection was found in $4.6 \%, 4.2 \%, 1.8 \%, 1.2 \%$ and $1.6 \%$ of patients aged $14-24,25-44,45-64,65-84$ and $\geqslant 85$ years, respectively ( $\mathrm{p}=0.002)$, with the positive rate of other respiratory viruses similar in different age groups (supplementary table S3). Influenza viral infection was more common in patients admitted to the ICU than patients in general wards $(32.9 \%$ versus $24.3 \%$; OR $1.52,95 \%$ CI $1.06-2.18 ; \mathrm{p}=0.023)$ (supplementary table S4). Typical bacteria were detected in 72 patients with viral infection, with S. pneumoniae and Klebsiella pneumoniae most commonly detected (supplementary table S5).

\section{Comparison of illness severity, complications and clinical outcomes between the influenza and} non-influenza viral infection groups

Among 915 patients with viral infection, the proportions of patients with CURB-65 $\geqslant 3$ (4.9\% versus 3.8\%; OR 0.76, 95\% CI 0.35-1.64; $\mathrm{p}=0.486)$ and $\mathrm{PaO}_{2} / \mathrm{FIO}_{2}<200 \mathrm{mmHg}(8.6 \%$ versus $5.1 \%$; OR $0.57,95 \% \mathrm{CI}$ $0.30-1.10 ; \mathrm{p}=0.092)$ on admission, and incidence of sepsis (40.1\% versus $39.6 \%$; OR 0.98 , 95\% CI $0.72-$ $1.33 ; \mathrm{p}=0.890)$ and hypoxaemia $(40.1 \%$ versus $37.2 \%$; OR $0.89,95 \%$ CI $0.65-1.22 ; \mathrm{p}=0.449)$ during hospitalisation in the influenza viral infection group did not significantly differ from those in the non-influenza viral infection group (table 3 and supplementary table S6). Additionally, there was no significant difference in ICU admission (8.3\% versus 5.4\%; OR 0.64, 95\% CI 0.34-1.20; $\mathrm{p}=0.157$ ), 90-day mortality (3.8\% versus $1.7 \%$; OR 0.43 , 95\% CI $0.15-1.26 ; \mathrm{p}=0.174)$ and length of hospital stay (10 versus 10 days; $\mathrm{p}=0.986$ ) between the two groups.

Compared with the influenza viral infection group, the multivariable adjusted odds ratios of CURB-65 $>3$ and $\mathrm{PaO}_{2} / \mathrm{FIO}_{2}<200 \mathrm{mmHg}$ on admission, and occurrence of sepsis and hypoxaemia during hospitalisation for the non-influenza viral infection group were 0.87 (95\% CI $0.26-2.84$ ), 0.72 (95\% CI 0.26-1.98), 1.00 (95\% CI $0.63-1.58)$ and 1.05 (95\% CI $0.66-1.65)$, respectively. The hazard ratio of 90-day mortality was 0.51 (95\% CI 0.13-1.91) (table 4). Additionally, diabetes and elevated procalcitonin (PCT) were associated with a higher proportion of CURB-65 $\geqslant 3$ and sepsis (supplementary table S7).

\section{Relationship between viral aetiology and disease severity, complications and outcomes}

On admission, the proportions of patient with CURB-65 $\geqslant 3(\mathrm{p}=0.803)$ and $\mathrm{PaO}_{2} / F \mathrm{IO}_{2}<200 \mathrm{mmHg}$ $(\mathrm{p}=0.476)$ were similar in the different viral infection groups (IFV, CoV, HMPV, HRV, AdV, PIV, RSV and two or more viruses) (figure 3). No significant difference was found in terms of demographic characteristics, underlying diseases, respiratory symptoms, C-reactive protein or PCT between the influenza viral infection group and any of the different non-influenza viral infection groups following Bonferroni correction. Higher proportions of consolidation on chest radiography $(83.7 \%$ versus $50.4 \%$; OR 
TABLE 3 Disease severity, complications and outcomes in the influenza and non-influenza viral infection groups

\begin{tabular}{|c|c|c|c|c|}
\hline & Influenza viral infection" & Non-influenza viral infection" & Mixed viral infection ${ }^{+}$ & p-value \\
\hline Patients & 581 & 240 & 94 & \\
\hline CURB- $65 \geqslant 3$ on admission & 28/571 (4.9) & $9 / 238(3.8)$ & $3(3.2)$ & 0.486 \\
\hline Sepsis & $233(40.1)$ & 95 (39.6) & 39 (41.5) & 0.890 \\
\hline Hypoxaemia $\S$ & $214 / 534(40.1)$ & $87 / 234(37.2)$ & $39 / 87(44.8)$ & 0.449 \\
\hline Length of hospital stay days & $10.0(8.0-14.0)$ & $10.0(7.0-14.0)$ & $11.0(8.0-14.3)$ & 0.986 \\
\hline In-hospital mortality & $16(2.8)$ & $1(0.4)$ & $1(1.1)$ & 0.062 \\
\hline 90-day mortality & $22(3.8)$ & $4(1.7)$ & $2(2.1)$ & 0.174 \\
\hline
\end{tabular}

Data are presented as $\mathrm{n}, \mathrm{n}(\%)$ or median (interquartile range), unless otherwise stated. CURB-65: confusion, urea $>7 \mathrm{mmol} \cdot \mathrm{L}^{-1}$, respiratory rate $\geqslant 30$ breaths $\cdot \mathrm{min}^{-1}$, blood pressure $<90 \mathrm{mmHg}$ (systolic) or $\leqslant 60 \mathrm{mmHg}$ (diastolic), age $\geqslant 65$ years; $P_{\mathrm{aO}_{2}}$ : arterial oxygen tension; FlO ${ }_{2}$ : inspiratory oxygen fraction; ICU: intensive care unit. "\#: only influenza virus with or without co-infection; " : any non-influenza respiratory viruses with or without co-infection; ${ }^{+}$: any two or more viruses; ${ }^{\S}: \mathrm{PaO}_{2} / \mathrm{FIO}_{2}<300 \mathrm{mmHg}$. p-values are for the influenza viral infection group versus the non-influenza viral infection group.

5.04, 95\% CI 2.31-10.98; $\mathrm{p}<0.001)$ but lower rates of diffuse bilateral pulmonary infiltration $(4.1 \%$ versus 36.8\%; OR 0.07, 95\% CI 0.02-0.30; $\mathrm{p}<0.001$ ) were found in the AdV group compared with the IFV group (supplementary table S8).

Although more patients with $\mathrm{AdV}$ infection had a temperature $>37.8^{\circ} \mathrm{C}$, the proportion of patients achieving clinical stability within $24 \mathrm{~h}(\mathrm{p}=0.205)$ and $72 \mathrm{~h}(\mathrm{p}=0.230)$ after hospitalisation was similar irrespective of viral aetiology (figure 4).

During hospitalisation, the frequency of hypoxaemia was $45.1 \%$ in the influenza viral infection group and was similar among the different viral infection groups $(\mathrm{p}=0.416)$. Although the proportion of sepsis was lower in the RSV group than that in the IFV (24.6\% versus $40.1 \%$; OR 0.49, 95\% CI 0.26-0.91; $\mathrm{p}=0.022$ ), $\operatorname{AdV}(24.6 \%$ versus $44.6 \%$; OR $0.40,95 \%$ CI $0.18-0.90 ; \mathrm{p}=0.025)$, HMPV (24.6\% versus $46.4 \%$; OR 0.38, 95\% CI 0.14-0.97; $\mathrm{p}=0.036)$ and $\mathrm{CoV}$ (24.6\% versus $48.3 \%$; OR 0.43, 95\% CI 0.14-0.98; $\mathrm{p}=0.042$ ) groups, the difference was not significant following Bonferroni correction. Additionally, no significant difference in 90 -day mortality $(\mathrm{p}=0.953)$ or length of hospital stay $(\mathrm{p}=0.185)$ was found between the different viral infection groups (figure 3).

Multivariable analysis showed no significant difference in the impact of different non-influenza respiratory viruses on risk of CURB-65 $\geqslant 3$ or $\mathrm{PaO}_{2} / \mathrm{FIO}_{2}<200 \mathrm{mmHg}$ on admission, and occurrence of sepsis or hypoxaemia during hospitalisation, and 90-day mortality was not significantly different from that of influenza viral infection, after adjustment for confounding factors ( $\mathrm{p}>0.05$ for all) (table 4 ).

\section{Discussion}

Here, we performed a large multicentre prospective observational study (conducted in 34 hospitals) in mainland China to systemically investigate the impact of non-influenza respiratory viruses in the adult immunocompetent population, relative to that of IFV. Our results indicated that the effect of non-influenza respiratory viruses on illness severity, complications and outcomes in immunocompetent patients with CAP is similar to that associated with IFV-related respiratory diseases.

In the GLIMP [19] and EPIC studies [20], viral CAP diagnosis was 37.2\% in Asia and 23\% in the USA, similar to our results (39.2\%). Studies of adult CAP in China from 2001 and 2005 showed that bacterial aetiology (atypical and other bacteria) was much higher than viral causes (30.3-53.1\% versus $10.6-19.0 \%$ ) [21-25], whereas recent CAP aetiology studies from 2009 and 2016 in China revealed an increased detection of viral infections (21.1\% versus 34.9\%) and a decline of bacterial infections (7.8-24.8\%) [14, 2629], similar to the trends reported in European countries and the USA [30]. The use of new molecular diagnostic methods rather than paired serum antibody titres might explain the higher rate of viral detection. According to the recent epidemic surveillance data, with the exception of IFV, the primary causes of non-influenza viral pneumonia in China were AdV, RSV, CoVs, PIV, HRV and HMPV, with these viruses representing the main focus of this study [14, 26, 29, 31-34].

Non-influenza respiratory viruses accounted for nearly a third of the patients with viral pneumonia in this study. However, HRV was uncommon compared with the EPIC study, where it was the most common 
TABLE 4 Association of different viruses with CURB-65 $\geqslant 3$ and arterial oxygen tension $\left(\mathrm{PaO}_{2}\right) /$ inspiratory oxygen fraction $\left(F \mid \mathrm{O}_{2}\right)<200 \mathrm{mmHg}$ on admission, occurrence of hypoxaemia and sepsis during hospitalisation, and 90-day mortality in multivariable analysis $\#$

\begin{tabular}{|c|c|c|c|c|c|c|c|c|c|c|}
\hline \multirow[t]{2}{*}{ Virus } & \multicolumn{2}{|c|}{$\begin{array}{l}\text { CURB- } 65 \geqslant 3 \\
\text { on admission }\end{array}$} & \multicolumn{2}{|c|}{$\begin{array}{c}\mathrm{PaO}_{2} / \mathrm{FlO}_{2}<200 \mathrm{mmHg} \\
\text { on admission }\end{array}$} & \multicolumn{2}{|c|}{$\begin{array}{l}\text { Sepsis during } \\
\text { hospitalisation }\end{array}$} & \multicolumn{2}{|c|}{$\begin{array}{l}\text { Hypoxaemia during } \\
\text { hospitalisation }\end{array}$} & \multicolumn{2}{|c|}{ 90-day mortality } \\
\hline & OR $(95 \% \mathrm{Cl})$ & p-value & OR $(95 \% \mathrm{Cl})$ & p-value & OR $(95 \% \mathrm{CI})$ & p-value & OR $(95 \% \mathrm{CI})$ & p-value & HR (95\% CI) & p-value \\
\hline IFV & Reference & & Reference & & Reference & & Reference & & Reference & \\
\hline Non-IFV I & $0.87(0.26-2.84)$ & 0.811 & $0.72(0.26-1.98)$ & 0.519 & $1.00(0.63-1.58)$ & 0.993 & $1.05(0.66-1.65)$ & 0.842 & $0.51(0.13-1.91)$ & 0.314 \\
\hline CoV & $0.51(0.04-6.64)$ & 0.600 & $0.36(0.02-5.78)$ & 0.469 & $1.25(0.46-3.40)$ & 0.659 & $1.38(0.52-3.66)$ & 0.514 & $3.33(0.30-36.80)$ & 0.327 \\
\hline HMPV & $0.88(0.08-9.31)$ & 0.916 & $0.75(0.07-8.05)$ & 0.810 & $1.63(0.64-4.19)$ & 0.307 & $1.45(0.57-3.67)$ & 0.436 & $7.39(0.54-10.16)$ & 0.135 \\
\hline HRV & $3.74(0.24-17.42)$ & 0.344 & $2.33(0.22-24.75)$ & 0.483 & $1.86(0.64-5.40)$ & 0.257 & $1.81(0.64-5.13)$ & 0.265 & NA & \\
\hline AdV & $0.87(0.11-6.71)$ & 0.892 & $1.29(0.29-5.79)$ & 0.742 & $0.82(0.37-1.80)$ & 0.629 & $0.89(0.40-2.00)$ & 0.779 & $0.10(0.04-2.62)$ & 0.170 \\
\hline PIV & $2.37(0.23-24.05)$ & 0.464 & NA & & $1.40(0.53-3.71)$ & 0.493 & $1.14(0.43-3.03)$ & 0.786 & NA & \\
\hline RSV & $0.59(0.06-5.77)$ & 0.653 & $1.11(0.19-6.36)$ & 0.905 & $0.56(0.23-1.39)$ & 0.209 & $0.55(0.22-1.38)$ & 0.204 & $4.60(0.36-58.65)$ & 0.240 \\
\hline$\geqslant 2$ viruses & $0.66(0.10-4.27)$ & 0.661 & $0.62(0.15-2.64)$ & 0.618 & $1.08(0.52-2.22)$ & 0.838 & $1.14(0.57-2.28)$ & 0.713 & $0.16(0.01-2.50)$ & 0.190 \\
\hline
\end{tabular}

CURB-65: confusion, urea $>7 \mathrm{mmol} \cdot \mathrm{L}^{-1}$, respiratory rate $\geqslant 30$ breaths $\mathrm{min}^{-1}$, blood pressure $<90 \mathrm{mmHg}$ (systolic) or $\leqslant 60 \mathrm{mmHg}$ (diastolic), age $\geqslant 65$ years; IFV: influenza virus types A and

B; CoV: human coronavirus; HMPV: human metapneumovirus; HRV: human rhinovirus; AdV: adenovirus; PIV: parainfluenza virus; RSV: respiratory syncytial virus; NA: not available.

\#: co-infection, fever, elevated procalcitonin, leukocytosis, lobar consolidation and all other variables with $p<0.2$ in the univariate analysis were included in the multivariable regression model; the variables included in the multivariable adjusted regression analysis are shown in supplementary table S7; " : non-influenza respiratory viruses including CoV, HMPV, HRV, AdV, PIV and RSV. 

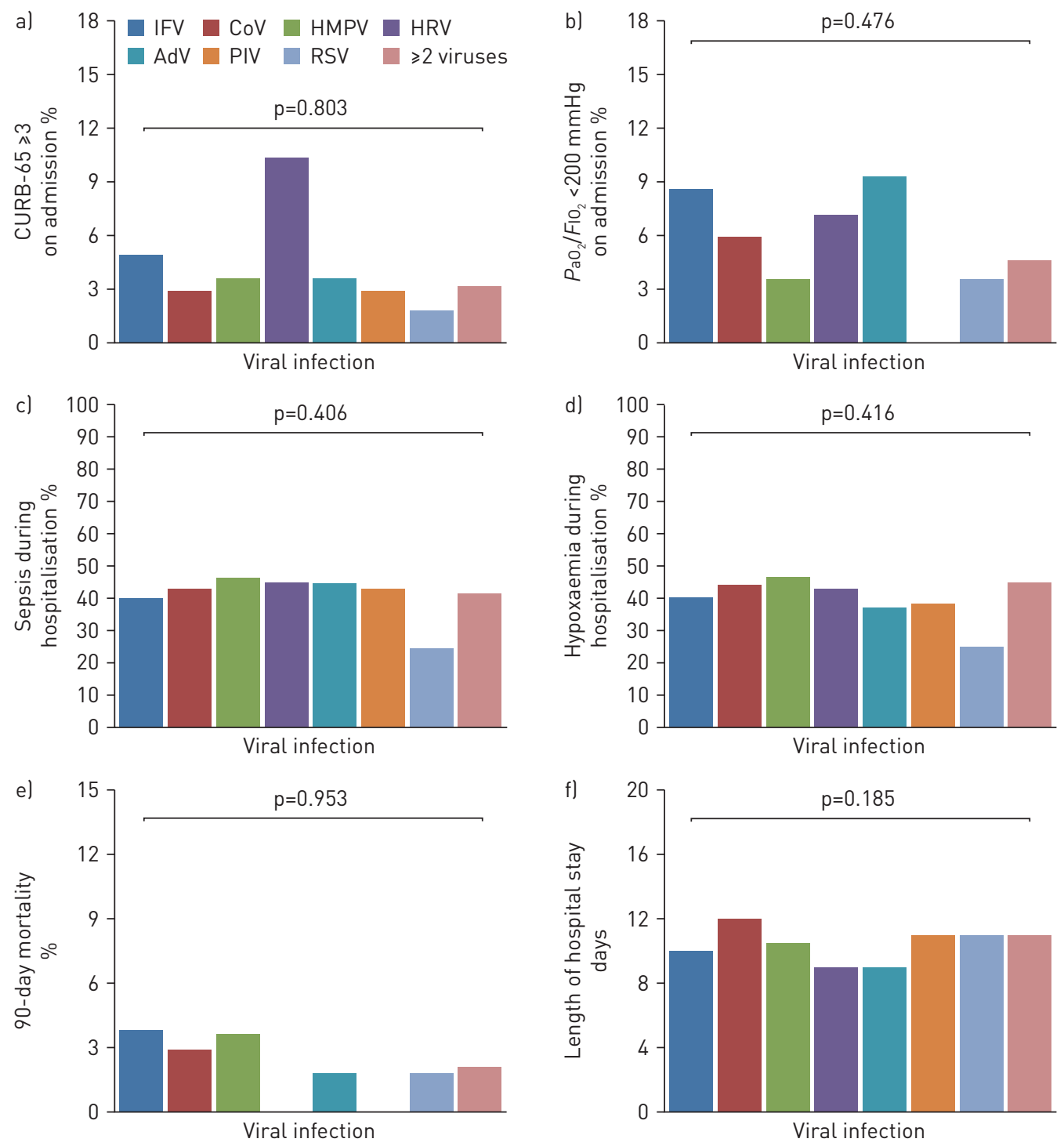

FIGURE 3 a, b) Illness severity on admission, c, d) complications during hospitalisation and e, f) outcomes of hospitalised community-acquired pneumonia patients with viral infections. CURB-65: confusion, urea $>7 \mathrm{mmol} \cdot \mathrm{L}^{-1}$, respiratory rate $\geqslant 30$ breaths $\cdot \mathrm{min}^{-1}$, blood pressure $<90 \mathrm{mmHg}$ (systolic) or $\leqslant 60 \mathrm{mmHg}$ (diastolic), age $\geqslant 65$ years; $\mathrm{PaO}_{2}$ : arterial oxygen tension; $\mathrm{FlO}_{2}$ : inspiratory oxygen fraction; IFV: influenza virus types $A$ and $B$; CoV: human coronavirus; HMPV: human metapneumovirus; HRV: human rhinovirus; AdV: adenovirus; PIV: parainfluenza virus; RSV: respiratory syncytial virus. On admission, the proportions of patients with a) CURB-65 $\geqslant 3(p=0.803)$ and b) $\mathrm{PaO}_{2} / \mathrm{FlO}_{2}<200 \mathrm{mmHg}(\mathrm{p}=0.476)$ were comparable in the different viral infection groups. During hospitalisation, no differences in the incidence of $c)$ sepsis $(p=0.406)$ and d) hypoxaemia ( $p=0.416$ ) were found among the different viral infection groups. e) 90-day mortality $(p=0.953)$ and $f)$ length of hospitalisation $(p=0.185)$ showed no statistically significant differences among the different viral infection groups.

viral pathogen [20]. According to recent research and meta-analysis, HRV was the most common virus isolated from patients with COPD, with detection in $23.0 \%$ of exacerbated cases $[35,36]$. However, only $5.1 \%$ (120 out of 2336) of the patients in our cohort had COPD compared with $42 \%$ (968 out of 2320) in the EPIC study [20] and 26\% (759 out of 3149) in the GLIMP study [19]. This difference might be due to the younger age (median 59.0 versus 69.0 years) and fewer current/ex-smokers (31.3\% versus $42.3 \%$ ) among our patients [19]. Additionally, RAdOVANOvic et al. [19] found a higher prevalence of HRV in North America relative to other continents, including Asia, Europe, Africa and Oceania (26.7\% versus $2.8 \% ; \mathrm{p}<0.001$ ), suggesting that climate, geographical position and local epidemiological trends might also influence the prevalence of viruses.

Consistent with previous studies, we observed similar clinical features among the different viral infection groups [37]. Although diffuse bilateral infiltrates were more common in IFV infection cases, further 


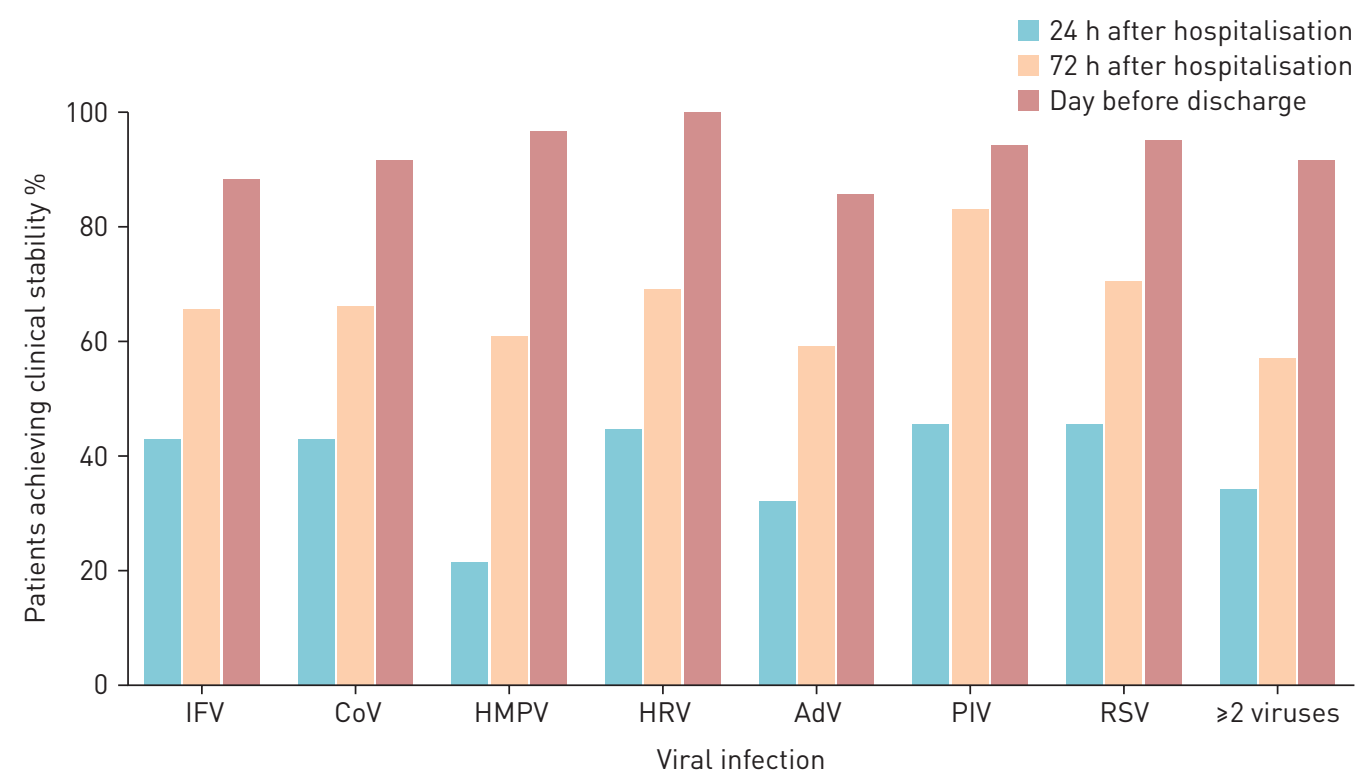

FIGURE 4 Proportion of patients achieving clinical stability 24 and $72 \mathrm{~h}$ after hospitalisation and the day before discharge. IFV: influenza virus types A and B; CoV: human coronavirus; HMPV: human metapneumovirus; HRV: human rhinovirus; AdV: adenovirus; PIV: parainfluenza virus; RSV: respiratory syncytial virus. The proportions of patients that achieved clinical stability were similar irrespective of viral aetiology within $24 \mathrm{~h}$ $(p=0.205)$ and $72 \mathrm{~h}(\mathrm{p}=0.230)$ after hospitalisation.

analysis showed that the difference only remained significant between IFV and AdV infection groups following Bonferroni correction. As previously reported, AdV infection was more commonly observed in young adults and more frequently appeared as consolidation than other viruses $[38,39]$. The high rate of elevated lactate dehydrogenase associated with AdV infection might reflect the possibility of hepatitis [40]. Moreover, we found a high proportion of hypoxaemia associated with HMPV and HRV infection. However, none of the clinical factors was specific enough to reliably discriminate between pneumonia caused by IFV and other viral pathogens.

Our data showed that the severity of pneumonia caused by non-influenza respiratory viruses was similar to that caused by IFV, which agrees with reports by GILCA et al. [41] and BJARNASON et al. [42]. Previous studies had reported that the spread of virus into the bronchial epithelium could induce respiratory airway injury and release of cytokines. Although the induced cytokine profiles might vary by virus, they converge on a common end pathway and result in similar diffuse alveolar damage [43,44]. In the present study, we found that comorbidities but not the type of viruses were independently associated with sepsis and hypoxaemia in patients with viral pneumonia. For elderly hospitalised patients with respiratory symptoms, RSV, HMPV and PIV were even associated with a higher mortality and more complications compared with IFV [45-49].

The impact of bacterial co-infection on disease severity and mortality had been reported in patients with viral infections $[18,49,50]$. However, detecting all of the concomitant bacterial infection was difficult due to the limitations in traditional methods, the few molecular diagnostic tests approved for bacteria identification [51] and the high rate of pre-sampling antibiotic use. According to a previous study, a PCT threshold of $\geqslant 0.5 \mathrm{ng} \cdot \mathrm{mL}^{-1}$ resulted in a specificity of $72.5 \%$ for bacterial identification [52]. Additionally, fever, leukocytosis and lobar consolidation have also been used to predict bacterial pneumonia [30]. After adjusting for viral-bacterial co-detection, elevated PCT, leukocytosis, fever and lobar consolidation in multivariate analysis, the non-influenza viral infection group was still confirmed to be comparable with the influenza viral infection group regarding disease severity, complications and mortality.

Our study offers critical insights into and recognition of non-influenza respiratory viruses among patients requiring admission to the hospital and potentially the ICU. In some randomised controlled trials and observational studies, rapid recognition of viruses was not associated with reducing the proportion of antibiotic use, early de-escalation or decreased hospital stay [53-58]. However, the duration of antibiotic use was reduced in patients with influenza-like illness, asthma and infective exacerbation of COPD [53, 55]. We recently completed a randomised controlled trial study (ClinicalTrials.gov identifier NCT03391076) which demonstrated that timely virus detection via PCR contributes to a decreased duration of antibiotics treatment in hospitalised CAP patients [59]. Furthermore, success has been achieved in patients with a 
decreased antibiotic prescription rate along with increased antiviral use following detection of IFV by rapid point-of-care testing [60]. Recognising the role of non-influenza respiratory viruses will promote the rapid development of antivirals, along the same lines as anti-influenza drug development (e.g. balozavir [61], pimodivir [62] and favipiravi [63]). Additionally, more novel antivirals are currently undergoing pre-clinical trials, including DAS181 for influenza [64], HMPV [65] and PIV [66], GS5806, ALS-8176 and AK0529 for RSV [67], and cidofovir for AdV [68]. Timely diagnosis of viral aetiology might help clinicians to optimise the use of antivirals and antibiotics in the era of targeted therapy.

There were some limitations in our study. First, viruses identified from nasopharyngeal swabs cannot easily differentiate lower and upper respiratory tract infections. In this study, only patients with radiologically confirmed pneumonia were enrolled and those with only upper respiratory tract infection had been excluded. Second, bacterial aetiology (atypical and other bacteria) was lower than that reported in previous studies (30.3-53.1\%) [21-25] in China from 2001 to 2005 [69]. This might be explained by increased pre-sampling antibiotic use, the relatively lower prevalence of comorbidities and less severe disease, resulting in lower bacterial detection in our study. Third, the PCR test was not used to detect typical bacterial pathogens, as it has not been recommended by the IDSA/American Society for Microbiology guidelines [51]. Fourth, we did not include immunosuppressed patients in this study and therefore our results cannot be generalised to that patient subset.

\section{Conclusions}

These findings suggest that complications were common in patients with non-influenza viral pneumonia and the impact of non-influenza respiratory viruses on clinical outcomes was comparable with that of IFV in immunocompetent adult patients with CAP. The increasing recognition of the significant role of non-influenza respiratory viruses might promote the development of CAP management procedures for immunocompetent adult patients.

Acknowledgements: We would like to thank all the physicians from the 34 hospitals who participated in CAP-China.

Author contributions: B. Cao, F. Zhou, Y. Wang, L. Gu, Y. Liu, B. Liu and C. Wang conceived of the project. B. Cao and F. Zhou performed the analysis and drafted the paper, and all authors critically revised the manuscript for important intellectual content and gave final approval for the version to be published. All authors agree to be accountable for all aspects of the work in ensuring that questions related to the accuracy or integrity of any part of the work are appropriately investigated and resolved. B. Cao takes full responsibility for the data and analysis.

Conflict of interest: None declared.

Support statement: This study was supported by grants from the National Science Fund for Distinguished Young Scholars (81425001/H0104), the Innovation Fund for Medical Sciences from the Chinese Academy of Medical Sciences (2018-I2M-1-003), the National Key Technology Support Program from the Ministry of Science and Technology (2015BAI12B11), and the Beijing Science and Technology Project (D151100002115004). Funding information for this article has been deposited with the Crossref Funder Registry.

\section{References}

Mandell LA. Community-acquired pneumonia: an overview. Postgrad Med 2015; 127: 607-615.

2 Burk M, El-Kersh K, Saad M, et al. Viral infection in community-acquired pneumonia: a systematic review and meta-analysis. Eur Respir Rev 2016; 25: 178-188.

Cavallazzi R, Ramirez JA. Influenza and viral pneumonia. Clin Chest Med 2018; 39: 703-721.

Ruuskanen O, Lahti E, Jennings LC, et al. Viral pneumonia. Lancet 2011; 377: 1264-1275.

Haas LE, Thijsen SF, van Elden L, et al. Human metapneumovirus in adults. Viruses 2013; 5: 87-110.

Griffiths C, Drews SJ, Marchant DJ. Respiratory syncytial virus: infection, detection, and new options for prevention and treatment. Clin Microbiol Rev 2017; 30: 277-319.

7 Branche AR, Falsey AR. Parainfluenza virus infection. Semin Respir Crit Care Med 2016; 37: 538-554.

8 Choi SH, Huh JW, Hong SB, et al. Clinical characteristics and outcomes of severe rhinovirus-associated pneumonia identified by bronchoscopic bronchoalveolar lavage in adults: comparison with severe influenza virus-associated pneumonia. J Clin Virol 2015; 62: 41-47.

9 Vabret A, Mourez T, Gouarin S, et al. An outbreak of coronavirus OC43 respiratory infection in Normandy, France. Clin Infect Dis 2003; 36: 985-989.

10 Liao RS, Appelgate DM, Pelz RK. An outbreak of severe respiratory tract infection due to human metapneumovirus in a long-term care facility for the elderly in Oregon. J Clin Virol 2012; 53: 171-173.

11 Jacobs SE, Lamson DM, Soave R, et al. Clinical and molecular epidemiology of human rhinovirus infections in patients with hematologic malignancy. J Clin Virol 2015; 71: 51-58.

12 Mandell LA, Wunderink RG, Anzueto A, et al. Infectious Diseases Society of America/American Thoracic Society consensus guidelines on the management of community-acquired pneumonia in adults. Clin Infect Dis 2007; 44: Suppl. 2, S27-S72.

13 Weinberg GA, Schnabel KC, Erdman DD, et al. Field evaluation of TaqMan Array Card (TAC) for the simultaneous detection of multiple respiratory viruses in children with acute respiratory infection. J Clin Virol 2013; 57: 254-260 
14 Qu JX, Gu L, Pu ZH, et al. Viral etiology of community-acquired pneumonia among adolescents and adults with mild or moderate severity and its relation to age and severity. BMC Infect Dis 2015; 15: 89.

15 Sanz F, Gimeno C, Lloret T, et al. Relationship between the presence of hypoxemia and the inflammatory response measured by C-reactive protein in bacteremic pneumococcal pneumonia. Eur Respir J 2011; 38: Suppl. 55, 2492.

16 Singer M, Deutschman CS, Seymour CW, et al. The Third International Consensus Definitions for Sepsis and Septic Shock (Sepsis-3). JAMA 2016; 315: 801-810.

17 Lim WS, Baudouin SV, George RC, et al. BTS guidelines for the management of community acquired pneumonia in adults: update 2009. Thorax 2009; 64: Suppl. 3, iiil-iii55.

18 Voiriot G, Visseaux B, Cohen J, et al. Viral-bacterial coinfection affects the presentation and alters the prognosis of severe community-acquired pneumonia. Crit Care 2016; 20: 375.

19 Radovanovic D, Sotgiu G, Jankovic M, et al. An international perspective on hospitalized patients with viral community-acquired pneumonia. Eur J Intern Med 2019; 60: 54-70.

20 Jain S, Self WH, Wunderink RG, et al. Community-acquired pneumonia requiring hospitalization among U.S. adults. N Engl J Med 2015; 373: 415-427.

21 Huang HH, Zhang YY, Xiu QY, et al. Community-acquired pneumonia in Shanghai, China: microbial etiology and implications for empirical therapy in a prospective study of 389 patients. Eur J Clin Microbiol Infect Dis 2006; 25: 369-374.

22 Liu Y, Chen M, Zhao T, et al. Causative agent distribution and antibiotic therapy assessment among adult patients with community acquired pneumonia in Chinese urban population. BMC Infect Dis 2009; 9: 31.

23 Lui G, Ip M, Lee N, et al. Role of "atypical pathogens" among adult hospitalized patients with community-acquired pneumonia. Respirology 2009; 14: 1098-1105.

24 Ngeow YF, Suwanjutha S, Chantarojanasriri T, et al. An Asian study on the prevalence of atypical respiratory pathogens in community-acquired pneumonia. Int J Infect Dis 2005; 9: 144-153.

25 Song JH, Oh WS, Kang CI, et al. Epidemiology and clinical outcomes of community-acquired pneumonia in adult patients in Asian countries: a prospective study by the Asian network for surveillance of resistant pathogens. Int $J$ Antimicrob Agents 2008; 31: 107-114.

26 Gong C, Zhang T, Luo M, et al. Distribution of the atypical pathogens of community-acquired pneumonia to disease severity. J Thorac Dis 2018; 10: 5991-6001.

27 Tao RJ, Luo XL, Xu W, et al. Viral infection in community acquired pneumonia patients with fever: a prospective observational study. J Thorac Dis 2018; 10: 4387-4395.

28 Luan Y, Sun Y, Duan S, et al. Pathogenic bacterial profile and drug resistance analysis of community-acquired pneumonia in older outpatients with fever. J Int Med Res 2018; 46: 4596-4604.

29 Zhan Y, Yang Z, Chen R, et al. Respiratory virus is a real pathogen in immunocompetent community-acquired pneumonia: comparing to influenza like illness and volunteer controls. BMC Pulm Med 2014; 14 : 144.

30 Musher DM, Abers MS, Bartlett JG. Evolving understanding of the causes of pneumonia in adults, with special attention to the role of pneumococcus. Clin Infect Dis 2017; 65: 1736-1744.

31 Liu YF, Gao Y, Chen MF, et al. Etiological analysis and predictive diagnostic model building of community-acquired pneumonia in adult outpatients in Beijing, China. BMC Infect Dis 2013; 13: 309.

32 Cao B, Ren LL, Zhao F, et al. Viral and Mycoplasma pneumoniae community-acquired pneumonia and novel clinical outcome evaluation in ambulatory adult patients in China. Eur J Clin Microbiol Infect Dis 2010; 29: 1443-1448.

33 Li X, Chen B, Zhang S, et al. Rapid detection of respiratory pathogens for community-acquired pneumonia by capillary electrophoresis-based multiplex PCR. SLAS Technol 2019; 24: 105-116.

34 Chen $\mathrm{H}$, Weng $\mathrm{H}$, Lin $\mathrm{M}$, et al. The clinical significance of FilmArray Respiratory Panel in diagnosing community-acquired pneumonia. Biomed Res Int 2017; 2017: 7320859.

35 Wilkinson TMA, Aris E, Bourne S, et al. A prospective, observational cohort study of the seasonal dynamics of airway pathogens in the aetiology of exacerbations in COPD. Thorax 2017; 72: 919-927.

36 Jafarinejad H, Moghoofei M, Mostafaei S, et al. Worldwide prevalence of viral infection in AECOPD patients: a meta-analysis. Microb Pathog 2017; 113: 190-196.

37 Jain S. Epidemiology of viral pneumonia. Clin Chest Med 2017; 38: 1-9.

38 Tan D, Zhu H, Fu Y, et al. Severe community-acquired pneumonia caused by human adenovirus in immunocompetent adults: a multicenter case series. PLoS One 2016; 11: e0151199.

39 Cao B, Huang $\mathrm{GH}, \mathrm{Pu} \mathrm{ZH}$, et al. Emergence of community-acquired adenovirus type 55 as a cause of community-onset pneumonia. Chest 2014; 145: 79-86.

40 Lynch JP. Adenovirus: epidemiology, global spread of novel serotypes, and advances in treatment and prevention. Semin Respir Crit Care Med 2016; 37: 586-602.

41 Gilca R, Amini R, Douville-Fradet M, et al. Other respiratory viruses are important contributors to adult respiratory hospitalizations and mortality even during peak weeks of the influenza season. Open Forum Infect Dis 2014; 1 : ofu086.

42 Bjarnason A, Westin J, Lindh M, et al. Incidence, etiology, and outcomes of community-acquired pneumonia: a population-based study. Open Forum Infect Dis 2018; 5: ofy010.

43 Deng JC. Viral-bacterial interactions - therapeutic implications. Influenza Other Respir Viruses 2013; 7: Suppl. 3, 24-35.

44 Shah RD, Wunderink RG. Viral pneumonia and acute respiratory distress syndrome. Clin Chest Med 2017; 38: $113-125$.

45 Widmer K, Zhu Y, Williams JV, et al. Rates of hospitalizations for respiratory syncytial virus, human metapneumovirus, and influenza virus in older adults. J Infect Dis 2012; 206: 56-62.

46 Widmer K, Griffin MR, Zhu Y, et al. Respiratory syncytial virus- and human metapneumovirus-associated emergency department and hospital burden in adults. Influenza Other Respir Viruses 2014; 8: 347-352.

47 Ackerson B, Tseng HF, Sy LS, et al. Severe morbidity and mortality associated with respiratory syncytial virus versus influenza infection in hospitalized older adults. Clin Infect Dis 2019; 69: 197-203.

48 van Asten L, van den Wijngaard C, van Pelt W, et al. Mortality attributable to 9 common infections: significant effect of influenza A, respiratory syncytial virus, influenza B, norovirus, and parainfluenza in elderly persons. J Infect Dis 2012; 206: 628-639. 
Lee N, Lui GC, Wong KT, et al. High morbidity and mortality in adults hospitalized for respiratory syncytial virus infections. Clin Infect Dis 2013; 57: 1069-1077.

50 Joseph C, Togawa Y, Shindo N. Bacterial and viral infections associated with influenza. Influenza Other Respir Viruses 2013; 7: Suppl. 2, 105-113.

51 Miller JM, Binnicker MJ, Campbell S, et al. A guide to utilization of the microbiology laboratory for diagnosis of infectious diseases: 2018 update by the Infectious Diseases Society of America and the American Society for Microbiology. Clin Infect Dis 2018; 67: e1-e94.

52 Self WH, Balk RA, Grijalva CG, et al. Procalcitonin as a marker of etiology in adults hospitalized with community-acquired pneumonia. Clin Infect Dis 2017; 65: 183-190.

53 Brendish NJ, Malachira AK, Armstrong L, et al. Routine molecular point-of-care testing for respiratory viruses in adults presenting to hospital with acute respiratory illness (ResPOC): a pragmatic, open-label, randomised controlled trial. Lancet Respir Med 2017; 5: 401-411.

54 Andrews D, Chetty Y, Cooper BS, et al. Multiplex PCR point of care testing versus routine, laboratory-based testing in the treatment of adults with respiratory tract infections: a quasi-randomised study assessing impact on length of stay and antimicrobial use. BMC Infect Dis 2017; 17: 671.

55 Keske S, Ergonul O, Tutucu F, et al. The rapid diagnosis of viral respiratory tract infections and its impact on antimicrobial stewardship programs. Eur J Clin Microbiol Infect Dis 2018; 37: 779-783.

56 Semret M, Schiller I, Jardin BA, et al. Multiplex respiratory virus testing for antimicrobial stewardship: a prospective assessment of antimicrobial use and clinical outcomes among hospitalized adults. J Infect Dis 2017 216: 936-944.

57 Afzal Z, Minard CG, Stager CE, et al. Clinical diagnosis, viral PCR, and antibiotic utilization in community-acquired pneumonia. Am J Ther 2016; 23: e766-e772.

58 Hernes SS, Hagen E, Quarsten H, et al. No impact of early real-time PCR screening for respiratory viruses on length of stay and use of antibiotics in elderly patients hospitalized with symptoms of a respiratory tract infection in a single center in Norway. Eur J Clin Microbiol Infect Dis 2014; 33: 359-364.

59 Duan SC, Gu XY, Fan GH, et al. The clinical value of a new molecular point-of-care testing in hospitalized lower respiratory tract infection patients: a randomized controlled study. Am J Respir Crit Care Med 2019; 199 : A209.

60 Blatt SP, Yultyev A, Huang M, et al. Impact of respiratory virus molecular testing on antibiotic utilization in community-acquired pneumonia. Am J Infect Control 2017; 45: 1396-1398.

61 Hayden FG, Sugaya N, Hirotsu N, et al. Baloxavir marboxil for uncomplicated influenza in adults and adolescents N Engl J Med 2018; 379: 913-923.

62 Finberg RW, Lanno R, Anderson D, et al. Phase 2b study of pimodivir (JNJ-63623872) as monotherapy or in combination with oseltamivir for treatment of acute uncomplicated seasonal influenza A: TOPAZ trial. $J$ Infect Dis 2019; 219: 1026-1034.

63 Koszalka P, Tilmanis D, Hurt AC. Influenza antivirals currently in late-phase clinical trial. Influenza Other Respir Viruses 2017; 11: 240-246.

64 Moss RB, Hansen C, Sanders RL, et al. A phase II study of DAS181, a novel host directed antiviral for the treatment of influenza infection. J Infect Dis 2012; 206: 1844-1851.

65 Thammawat S, Sadlon TA, Adamson P, et al. Effect of sialidase fusion protein (DAS 181) on human metapneumovirus infection of Hep-2 cells. Antivir Chem Chemother 2015; 24: 161-165.

66 Salvatore M, Satlin MJ, Jacobs SE, et al. DAS181 for treatment of parainfluenza virus infections in hematopoietic stem cell transplant recipients at a single center. Biol Blood Marrow Transplant 2016; 22: 965-970.

67 McKimm-Breschkin JL, Jiang S, Hui DS, et al. Prevention and treatment of respiratory viral infections: presentations on antivirals, traditional therapies and host-directed interventions at the 5th ISIRV Antiviral Group conference. Antiviral Res 2018; 149: 118-142.

68 Grimley MS, Chemaly RF, Englund JA, et al. Brincidofovir for asymptomatic adenovirus viremia in pediatric and adult allogeneic hematopoietic cell transplant recipients: a randomized placebo-controlled phase II trial. Biol Blood Marrow Transplant 2017; 23: 512-521.

69 Peto L, Nadjm B, Horby P, et al. The bacterial aetiology of adult community-acquired pneumonia in Asia: a systematic review. Trans $R$ Soc Trop Med Hyg 2014; 108: 326-337. 